\title{
STUDI AWAL KARAKTERISTIK TEMPERATUR DAN TEKANAN PADA ALIRAN SIRKULASI ALAM DI FASILITAS UJI UNTAI FASSIP-02 MENGGUNAKAN SIMULASI CFD
}

\author{
Ainur Rosidi, Mulya Juarsa, Dedy Haryanto, Anhar R. Antariksawan, \\ dan Mukhsinun Hadi Kusuma \\ Pusat Teknologi dan Keselamatan Reaktor Nuklir \\ Badan Tenaga Nuklir Nasional (BATAN) \\ e-mail: ainur@batan.go.id
}

\begin{abstract}
FASSIP-02 loop is a test facility that is used for research and development of safety technologies for future nuclear power plants based on natural law. This test facility is designed to study natural circulation phenomena caused by differences in fluid density due to temperature differences in the one-phase heat dissipation system during the simulation of heat removal from the reactor core when an accident occurs. FASSIP-02 loop consists of piping components, water heating tanks, water cooling tanks and expansion tanks. The purpose of this study was to understand the conditions of temperature change and pressure of water working fluid based on temperature changes in the heater section which were simulated on the loop geometry FASSIP-02. The research method was carried out in a simulation of Computational Fluid Dynamics using FLUENT 6.3 software. The working fluid in the FASSIP-02 loop uses water with a temperature of $27^{\circ} \mathrm{C}$, the flow rate is varied $0.3 \mathrm{~m} / \mathrm{s}$ and $0.45 \mathrm{~m} / \mathrm{s}$, while the temperature in the heating section is $70^{\circ} \mathrm{C}$. CFD simulation results show that the increase in the working fluid temperature of the water with a flow rate of $0.3 \mathrm{~m} / \mathrm{s}$ after passing through the heating section is $39^{\circ} \mathrm{C}$, while the temperature increase of the working fluid of the water with a flow rate of $0.45 \mathrm{~m} / \mathrm{s}$ is $36.6^{\circ} \mathrm{C}$. Pressure drops at flow rates of $0.3 \mathrm{~m} / \mathrm{s}$ and $0.45 \mathrm{~m} / \mathrm{s}$ each occur in water working fluid before entering through WHT and after passing through the heating section.
\end{abstract}

Keywords: Temperature, Pressure, natural circulation, FASSIP-02 loop, CFD.

\section{PENDAHULUAN}

Sistem keselamatan pasif telah diadopsi di pembangkit listrik tenaga nuklir (PLTN) generasi IV karena mempunyai banyak keuntungan secara ekonomi dan bentuk yang sederhana. Setelah terjadinya kecelakanan nuklir di Fukushima Dai-ichi Jepang, dunia nuklir mulai melirik sistem pendingin pasif sebagai sistem keselamatan bantu ketika terjadi kecelakaan. Sistem keselamatan pasif ini diharapkan dapat beroperasi ketika seluruh sistem reaktor mengalami station blackout,untuk meningkatkan kemampuan dari sistem sirkulasi alam dalam membuang kalor pada waktu kecelakaan diperlukan pengembangan desain dan penelitian secara terus menerus sehingga mekanisme pembuangan panas secara sirkulasi alam dapat bekerja secara optimal.

Penelitian terkait fenomena sirkulasi alam telah dilakukan oleh peneliti sebelumnya oleh Kudariyawar et.al. melakukan eksperimen dan simulasi menggunakan Computational Fluid Dynamics (CFD) untuk mempelajari fenomena sirkulasi alam satu fasa dengan variasi beban kalor di bagian pemanas [1]. Tujuannya adalah untuk mengetahui karakteristik temperatur steady state dan transient di loop rectangular yang menggunakan fluida kerja garam cair. Penelitian tentang efek sudut kemiringan terhadap kestabilan aliran sirkulasi alam di dalam loop rectangular telah dipelajari oleh Krishnani et.al. [2]. Sedangkan efek kenaikan daya pada sistem pemanas terhadap ketidakstabilan pada loop rectangular sirkulasi alam juga di analisa secara numerik oleh Saha et.al. [3]. Wang et.al. menyelidiki fenomena di dalam loop sirkulasi alami untuk mempelajari karakteristik perpindahan aliran dan temperaturnya di dalampipa lurus maupun elbow [4]. Ekariansyah et.al. telah melakukan analisis untuk memahami pengaruh perbedaan elevasi antara posisi heater dan cooler terhadap fasilitas uji FASSIP-01 menggunakan simulasi program perhitungan RELAP5/SCDAP/Mod3.4 [5,6]. FASSIP-01 merupakan fasilitas uji sirkulasi alami yang telah dibangun sebelumnya dengan loop persegi panjang ukuran sedang dengan geometri panjang adalah 3,5 $\mathrm{m}$ dan tinggi $6 \mathrm{~m}$. Hasil simulasi menunjukkan distribusi temperatur antara air yang keluar dari heater dan air yang keluar dari cooler lebih besar pada posisi heater di atas atau sama dengan cooler. 
Pada FASSIP-02 sistem pendinginnya dilengkapi dengan heat pipe, penggunaan heat pipe sebagai alat penukar kalor secara pasif tanpa sumber listrik dari luar telah dilakukan oleh Kusuma et.al. hasil eksperimen dan simulasinya menunjukkan heat pipe memiliki thermal performance yang sangat baik untuk digunakan sebagai pembuang kalor dan dapat dijadikan model untuk membuat vertical straight wickless-heat pipe sebagai pendingin di kolam penyimpanan bahan bakar nuklir bekas [7].

FASSIP-02 mempunyai geometri skala besar dengan ketinggian 11 meter antara sumber kalor dan sumber pendingin. Sebelum fasilitas uji ini dibangun, Antariksawan et.al. telah melakukan perhitungan menggunakan RELAP5 untuk mendapatkan memperoleh kondisi operasi terbaik untuk melakukan eksperimen [8]. Simulasi dilakukan dengan berbagai nilai daya pemanas, kondisi isolasi pipa dan katup tangki ekspansi. Hasil yang diperoleh bahwa untuk semua kondisi operasi, jika diinginkan kondisi satu fasa cair, maka daya pemanas dijaga di bawah $10 \mathrm{~kW}$. Juarsa et.al. melakukan perhitungan analitik dengan beberapa korelasi untuk memperkirakan laju alir didalam loop sirkulasi alam FASSIP-02 [9]. Metode perhitungan dilakukan dengan menggunakan dua korelasi prinsip turunan dari gaya apung di bagian pemanas dan gaya gravitasi pada bagian pendingin.

Salah satu metode untuk mengetahui perilaku perubahan temperatur dan tekanan fluida kerja air di loop untai FASSIP-02 selama melewati bagian pemanas adalah menggunakan CFD. CFD merupakan perangkat lunak yang mampu menyelesaikan berbagai jenis aliran fluida dengan cara mensimulasikan aliran fluida inkompresibel/kompresibel, tunak/taktunak, aliran laminar/turbulen, aliran fluida Newtonian/non Newtonian, perpindahan panas konveksi baik konveksi alam maupun konveksi paksa dan gabungan konduksi/konveksi [10,11]. Perangkat lunak CFD tersebut mampu menyelesaikan persamaan Navier - Stokes dengan dasar persamaan kekekalan massa (kontinyuitas), kekekalan momentum serta kekekalan energi untuk aliran fluida yang melibatkan proses perpindahan panas [12].

Penelitian ini bertujuan untuk mempelajari karakteristik tekanan dan temperatur pada aliran fluida kerja yang melewati bagian tangki pemanas di dalam loop sirkulasi alam FASSIP-02 dengan menggunakan FLUENT 6.3. Temperatur pada bagian pemanas yang digunakan sebesar $70^{\circ} \mathrm{C}$, sedangkan inputan laju alir yang diberikan divariasikan $0,3 \mathrm{~m} / \mathrm{s}$ dan $0,45 \mathrm{~m} / \mathrm{s}$ yang didapatkan dari hasil perhitungan analitik [9].

\section{METODOLOGI \\ Desain Loop FASSIP-02}

Desain dari Loop FASSIP-02 ditunjukkan pada Gambar 1, terdiri dari komponen pipa berbahan SS 304 memiliki diameter 1 inci, Sch 20, water heating tank (WHT) terdiri dari tangki dengan tinggi $1 \mathrm{~m}$ dan diameter 24 inci, Sch 40 dan dilengkapi heater sebanyak 4 buah masingmasing dengan daya $5000 \mathrm{~W}$. Sedangkan water cooling tank (WCT) terdiri dari tangki yang terbuat dari carbon steel dengan tebal $6 \mathrm{~mm}$ berbentuk balok dengan dimensi $1 \mathrm{~m} \mathrm{x} 3 \mathrm{~m}$ x $2.75 \mathrm{~m}$ dan di lengkapi dengan alat penukar kalor heat pipe. Beda ketinggian antara sumber kalor dan sumber pendingin adalah 11 meter.

\section{Pemodelan Geometri dengan CFD}

Geometri dan dimensi sirkulasi alami loop rectangular dengan fluida kerja air ditunjukkan pada Gambar 2. Boundary condition yang dipakai dalam simulasi dengan menggunakan CFD ini adalah masukan berupa velocity inlet, kecepatan masuk fluida kerja air ke model simulasi yaitu 0,3 $\mathrm{m} / \mathrm{s}$ dan $0,45 \mathrm{~m} / \mathrm{s}$ dengan temperatur $27^{\circ} \mathrm{C}$. Pada dinding pipa sebelum melewati WHT di beri nama wall_inlet dengan panjang pipa $8 \mathrm{~m}$ dan dinding pipa yang keluar dari WHT diberi nama wall_outlet dengan panjang $7 \mathrm{~m}$. Dengan asumsi pada pipa wall_inlet dan pipa wall_outlet tidak ada kalor yang keluar. 


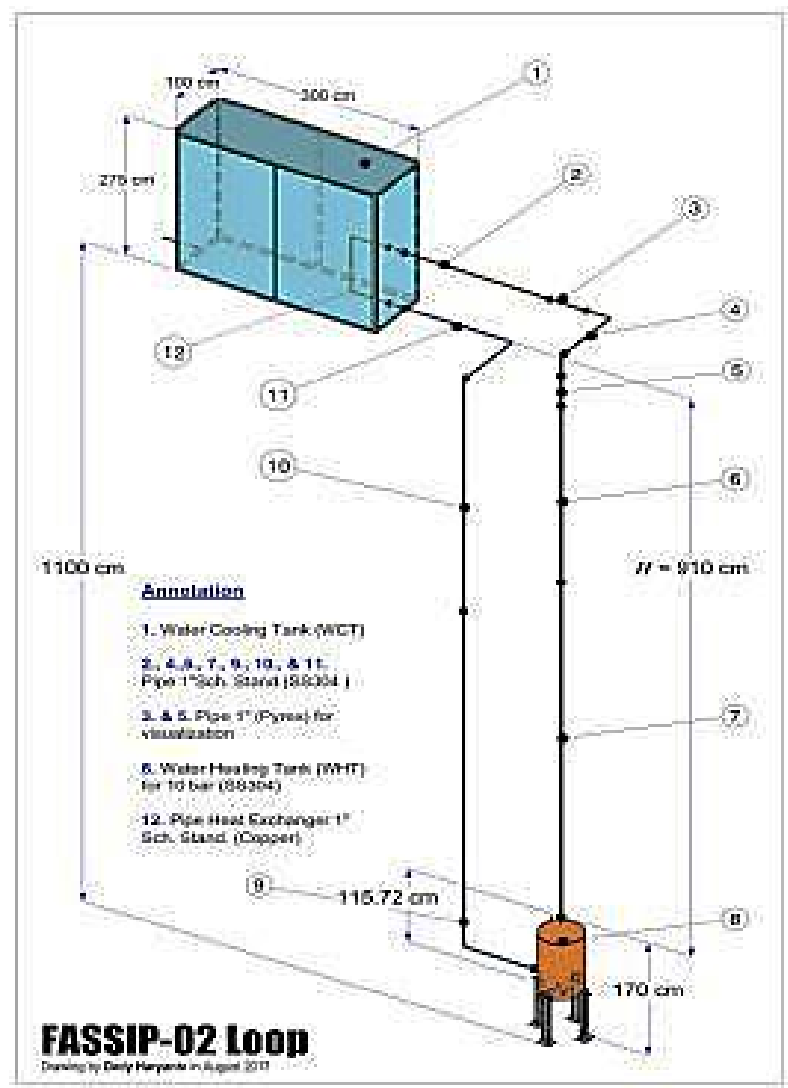

Gambar 1. Desain Loop FASSIP-02 [9]

Pada dinding pipa di dalam tangki sumber pemanas diberi kondisi batas sebagai wall heater dengan tinggi pipa $100 \mathrm{~cm}$ kearah vertical dan $30 \mathrm{~cm}$ kearah horizontal yang diberi temperatur $70^{\circ} \mathrm{C}$. Meshing pada input dan output fluida kerja air menggunakan interval count dengan dan type successive ratio menghasilkan total mesh edges 5, Sedangkan pada meshing face menggunakan interval size dengan type triangle 1 menghasilkan total mesh faces 27928. Parameter yang akan dihasilkan pada simulasi ini adalah distribusi temperatur dan tekanan pada fluida kerja air yang setelah melewati bagian pemanas.

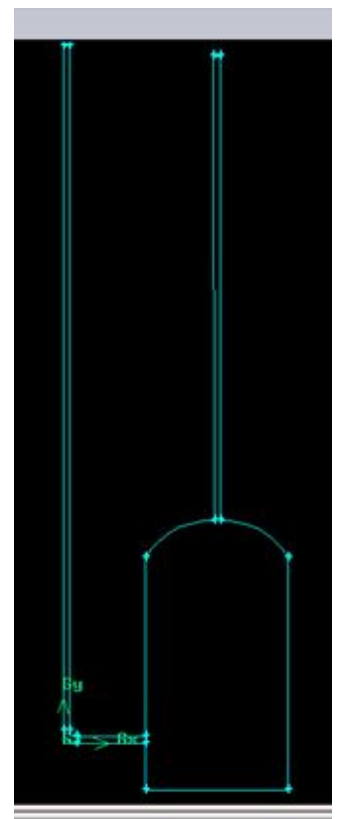

Gambar 2. Geometri model 


\section{HASIL DAN PEMBAHASAN}

Dari hasil simulasi yang telah dilakukan dapat dilihat pengaruh perubahan temperatur dan tekanan fluida kerja air yang mengalir melewati WHT berdasarkan variasi laju aliran di loop rectangular, kontur temperatur statik ditunjukan pada Gambar 3a dan Gambar 3b.

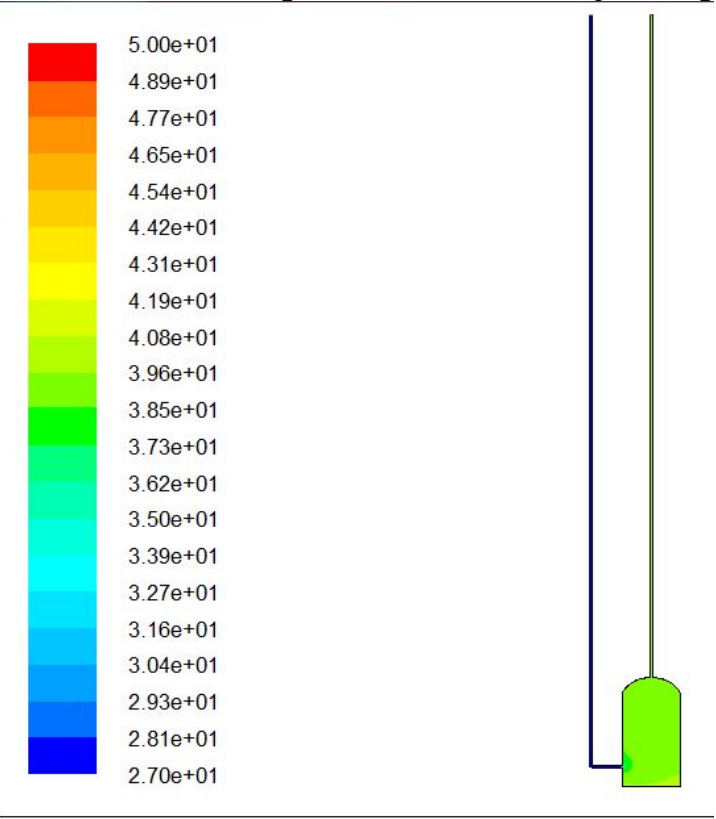

Contours of Static Temperature (c)

Gambar 3a. Kontur temperatur statik pada laju alir fluida kerja air $0,3 \mathrm{~m} / \mathrm{s}$

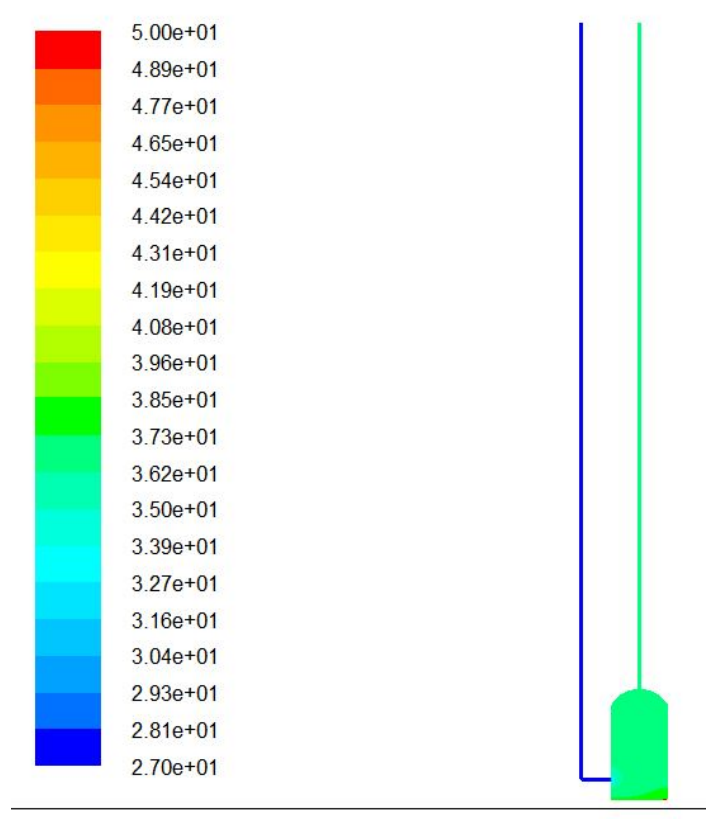

Contours of Static Temperature (c)

Gambar 3b. Kontur temperatur statik pada laju alir fluida kerja air $0.45 \mathrm{~m} / \mathrm{s}$

Dari Gambar 3a. dapat dilihat bahwa pada fluida kerja air di pipa wall_inlet sebelum melewati WHT dengan laju alir $0,3 \mathrm{~m} / \mathrm{s}$ distribusi temperaturnya merata, begitu juga pada fluida kerja air yang keluar dari WHT, distribusi temperatur yang dihasilkan merata sepanjang pipa wall_outlet. Profil kenaikan distribusi temperatur dengan laju alir 0,45 m/s yang ditunjukkan pada Gambar 3b. mempunyai tren yang sama seperti pada laju alir 0,3 m/s. Untuk memperjelas distribusi kenaikan pada loop FASSIP 02 ini dapat dilihat dari grafik pada Gambar 4a dan Gambar 4b.

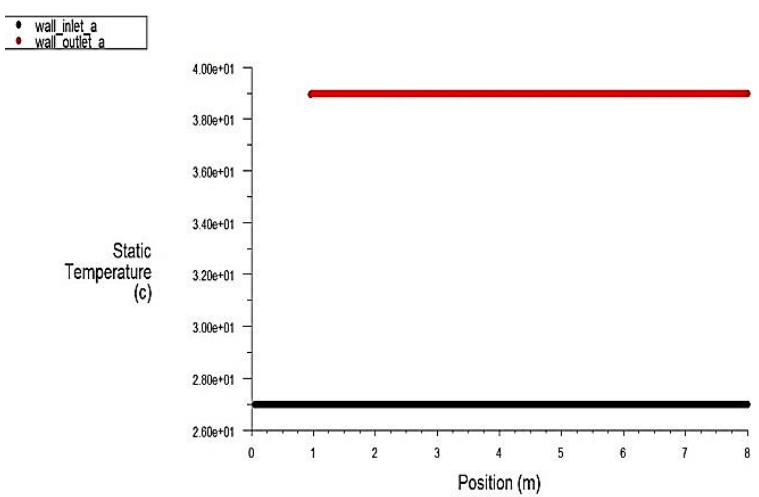

Gambar 4a. Distribusi temperature pada laju alir fluida kerja air $0,3 \mathrm{~m} / \mathrm{s}$

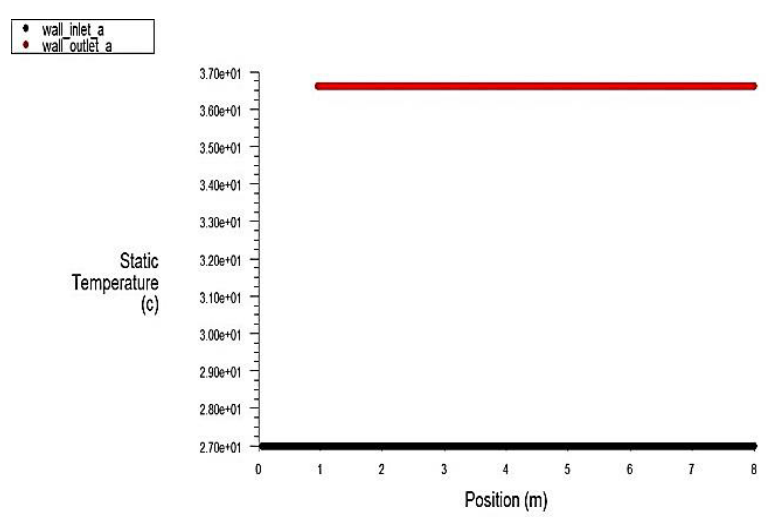

Gambar 4b. Distribusi temperature pada laju alir fluida kerja air $0,45 \mathrm{~m} / \mathrm{s}$

Dari Gambar 4a. dapat dilihat bahwa kenaikan temperatur fluida kerja air di pipa wall_outlet dengan laju alir $0,3 \mathrm{~m} / \mathrm{s}$ setelah melewati WHT adalah sebesar $39^{\circ} \mathrm{C}$, sedangkan kenaikan temperatur fluida kerja air dengan laju alir $0,45 \mathrm{~m} / \mathrm{s}$ pada pipa wall_outlet adalah $36 \cdot 6^{\circ} \mathrm{C}$. Hal ini 
disebabkan oleh semakin rendahnya nilai laju alir yang diberikan oleh fluida kerja air akan memperbesar perpindahan kalor secara konduksi dan konveksi yang diberikan oleh WHT pada fluida kerja air. Perubahan temperatur pada fluida air yang melewati WHT pada kedua variasi laju alir ini mengakibatkan kerapatan pada densitas fluida air di WHT berkurang, oleh karena kerapatan densitas di bagian pendingin yang ada diatas lebih besar maka akan terjadi sirkulasi dan gaya keatas karena perbedaan kerapatan densitas pada fluida air.

Profil perubahan tekanan fluida kerja air pada waktu sebelum dan setelah melewati WHT ditunjukkan pada Gambar 5

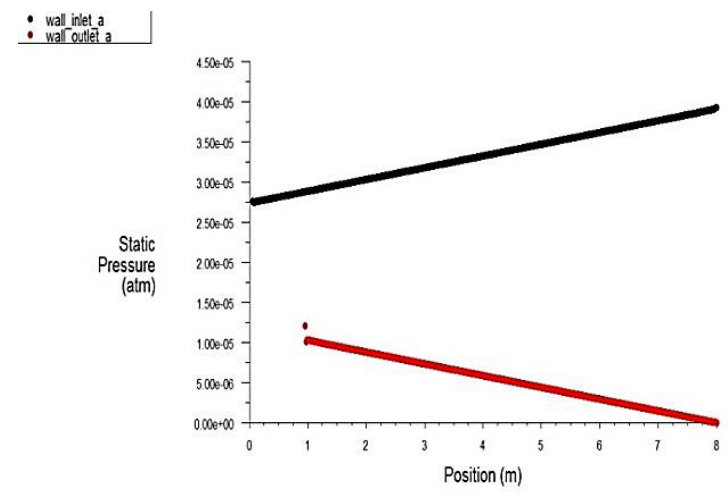

Gambar 5a. Distribusi tekanan pada laju alir fluida kerja air $0,3 \mathrm{~m} / \mathrm{s}$

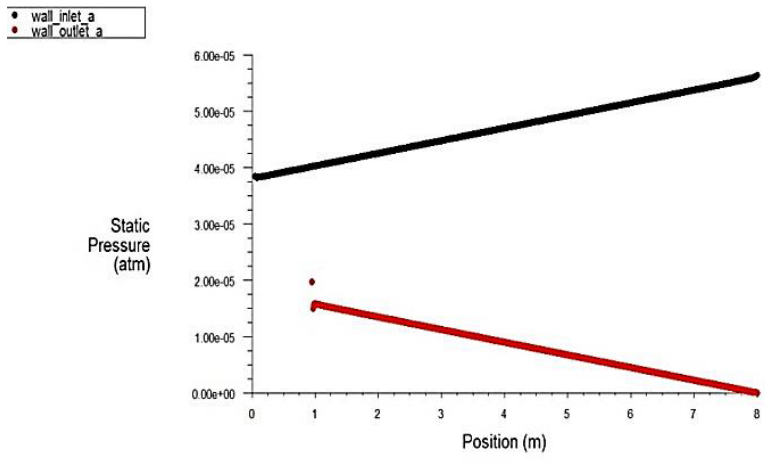

Gambar 5b. Distribusi tekanan pada laju alir fluida kerja air $0,45 \mathrm{~m} / \mathrm{s}$

Pada Gambar 5a. dapat dilihat bahwa penurunan tekanan secara linear pada fluida kerja air di pipa wall_inlet dengan laju alir $0,3 \mathrm{~m} / \mathrm{s}$ terjadi mulai ketinggian $8 \mathrm{~m}$ sampai masuk ke WHT. Fluida kerja air yang keluar dari WHT di pipa wall_outlet juga mengalami penurunan tekanan secara linear dari ketinggian $1 \mathrm{~m}$ sampai $8 \mathrm{~m}$. Profil penurunan tekanan dengan laju alir 0,45 m/s yang ditunjukkan pada Gambar 5b. mempunyai tren yang sama seperti pada laju alir 0,3 m/s. Fenomena terjadinya perubahan tekanan pada loop rectangular ini menyebabkan gaya dorong fluida kerja air keatas sehingga terbentuk aliran sirkulasi alam.

\section{SIMPULAN}

Hasil simulasi CFD menunjukkan bahwa kenaikan temperatur fluida kerja air di pipa wall_outlet dengan laju alir $0,3 \mathrm{~m} / \mathrm{s}$ setelah melewati WHT adalah sebesar $39^{\circ} \mathrm{C}$ pada, sedangkan kenaikan temperatur fluida kerja air dengan laju alir $0,45 \mathrm{~m} / \mathrm{s}$ pada pipa wall_outlet adalah $36.6^{\circ} \mathrm{C}$. Penurunan tekanan pada laju alir $0,3 \mathrm{~m} / \mathrm{s}$ dan $0,45 \mathrm{~m} / \mathrm{s}$ masing-masing terjadi pada fluida kerja air sebelum masuk melewati WHT dan setelah melewati WHT.

\section{UCAPAN TERIMA KASIH}

Penulis menyampaikan ucapan terimakasih kepada Kepala PTKRN BATAN atas dukungan dan kebijakannya dalam pelaksanaan penelitian ini. Ucapan terimakasih disampaikan kepada Program INSINAS Riset Pratama Kemitraan dari KEMENRISTEKDIKTI Tahun 2018 antara PTKRN BATAN dan FTUI untuk pengadaan dan pendanaan kegiatan penelitian.

\section{DAFTAR PUSTAKA}

[1]. Kudariyawar, Jayaraj Yallappa, Srivastava, Abhishek Kumar, Vaidya, Abhijeet Mohan, Maheshwari, Naresh Kumar, \& Satyamurthy, Polepalle. (2016). Computational and experimental investigation of steady state and transient characteristics of molten salt natural circulation loop. Applied Thermal Engineering,99,560-571. doi: https://doi.org/10.1016/j.applthermaleng.2015.12.114. 
[2]. Krishnani, Mayur, \& Basu, Dipankar N. (2017). Computational stability appraisal of rectangular natural circulation loop: Effect of loop inclination. Annals of Nuclear Energy, 107, 17-30. doi: https://doi.org/10.1016/j.anucene.2017.04.012.

[3]. Saha, Ritabrata, Ghosh, Koushik, Mukhopadhyay, Achintya, \& Sen, Swarnendu. (2018). Dynamic characterization of a single phase square natural circulation loop. Applied Thermal Engineering, 128, 1126-1138. doi: https://doi.org/10.1016/j.applthermaleng.2017.09.092.

[4]. Wang, J. Y., Chuang, T. J., \& Ferng, Y. M. (2013). CFD investigating flow and heat transfer characteristics in a natural circulation loop. Annals of Nuclear Energy, 58, 65-71. doi: https://doi.org/10.1016/j.anucene.2013.01.015.

[5]. Ekariansyah, Andi Sofrany, Tjahjono, Hendro, Juarsa, Mulya, \& Widodo, Surip. (2016). Analysis Of The Effect Of Elevation Difference Between Heater And Cooler Position In The Fassip-01 Test Loop Using Relap5. Sigma Epsilon-Buletin Ilmiah Teknologi Keselamatan Reaktor Nuklir, 19(1).

[6]. Tjahjono, H. (2017). Comprehensive Prediction of Thermosyphon Characteristics in Reactor Passive Cooling System Simulation Loop FASSIP-01 (Vol. 43).

[7]. Kusuma, Mukhsinun Hadi, Putra, Nandy, Antariksawan, Anhar Riza, Koestoer, Raldi Artono, Widodo, Surip, Ismarwanti, Sri, \& Verlambang, Brilian Tegar. (2018). Passive cooling system in a nuclear spent fuel pool using a vertical straight wickless-heat pipe. International Journal of Thermal Sciences, 126, 162-171. doi: https://doi.org/10.1016/j.ijthermalsci.2017.12.033.

[8]. Antariksawan, Anhar Riza, Widodo, Surip, Juarsa, Mulya, Haryanto, Dedy, Kusuma, Mukhsinun Hadi, \& Putra, Nandy. (2018). Simulation Of Operational Conditions Of Fassip02 Natural Circulation Cooling System Experimental Loop. Jurnal Sains dan Teknologi Nuklir Indonesia, 19(1), 40-52.

[9]. Juarsa, M, Antariksawan, AR, Kusuma, MH, Haryanto, D, \& Putra, N. (2018). Estimation of natural circulation flow based on temperature in the FASSIP-02 large-scale test loop facility. Paper presented at the IOP Conference Series: Earth and Environmental Science.

[10]. Cyranka, Jacek, Mucha, Piotr B., Titi, Edriss S., \& Zgliczyński, Piotr. (2018). Stabilizing the long-time behavior of the forced Navier-Stokes and damped Euler systems by large mean flow. Physica D: Nonlinear Phenomena, 369, 18-29. doi: https://doi.org/10.1016/j.physd.2017.12.010.

[11]. Jiang, X. W., Studer, E., \& Kudriakov, S. (2013). A simplified model of Passive Containment Cooling System in a CFD code. Nuclear Engineering and Design, 262, 579-588. doi: https://doi.org/10.1016/j.nucengdes.2013.06.010.

[12]. Ge, Jian, Tian, Wenxi, Qiu, Suizheng, \& Su, G. H. (2018). CFD investigation on thermal hydraulics of the passive residual heat removal heat exchanger (PRHR HX). Nuclear Engineering and Design, 327, 139-149. doi: https://doi.org/10.1016/j.nucengdes.2017.11.029. 